Grant, E. C., \& MacKintosh, J. H. A comparison of the social postures of some common laboratory rodents. Behaviour $1963,21,246-259$

Kimbrell, G. M. "Fighting response": A definitional problem. Psychological Record, 1968, 18, 639-640.

Knutson, J. F. The effects of shocking one member of a pair of rats. Psychonomic Science, 1971, 22, 265-266.

Kršiak, M., \& Steinberg, H. Psychopharmacological aspects of aggression: A review of the literature and some new experiments. Journal of Psychosomatic Research, 1969, 13, 243-252.

Powell, D. A., Francis, J., Bramin, M. J., \& Schneiderman, N. Frequency of attack in shock-elicited aggression as a function of the performance of individual rats. Journal of the Experimental Analysis of Behavior, 1969, 12, 817-823.

Reynierse, J. H. Submissive postures during shock-elicited aggression. Animal Behaviour, 1971, 19, 102-107.

Selekman, W., \& Meehan, E. An objective technique for recording shock-induced aggression in unrestrained pairs of rats. Journal of the Experimental Analysis of Behavior, 1974, 21, 177-180.
Thor, D. H., \& Ghiselli, W. B. Prolonged suppression of irritable aggression in rats by facial anesthesia. Psychological Reports, $1973,33,815-820$.

Thor, D. H., \& Ghiselli, W. B. Visual and social determinants of shock-elicited aggressive responding in rats. Animal Learning \& Behavior, 1974, 2, 74-76.

Thor, D. H., Ghiselli, W. B., \& Wilson, L. D. Vocalization as an objective measures of shock-elicited social aggression in rats. Animal Learning \& Behavior, 1973, 1, 263-267.

Ulrich, R. Pain as a cause of aggression. American Zoologist, $1966,6,643-662$.

Ulrich, R. E., \& Azrin, N. H. Reflexive fighting in response to aversive stimulation. Journal of the Experimental Analysis of Behavior, 1962, 5, 511-520.

(Received for publication March 27, 1974.)

\title{
Semantic factors in intentional and incidental sentence recall
}

\author{
SHELDON ROSENBERG*, WILLIAM J. SCHILLER, and JOAN A. SMITH \\ University of Illinois at Chicago Circle, Chicago, Ilinois 60680
}

\begin{abstract}
Independent groups were exposed to normal or anomalous sentences under an incidental-nonsemantic (letter estimation), incidental-semantic (familiarity rating), or intentional-only orientation. Written recall followed one presentation of the sentences in each group. None of the differences between intentional and incidental-semantic Ss was significant, and semantic coding facilitated recall performance for both normal and anomalous sentences but to a greater extent for normal sentences.
\end{abstract}

Rosenberg and Schiller (1971) found that when

*Requests for reprints should be sent to Sheldon Rosenberg, Department of Psychology, University of Illinois at Chicago Circle, Box 4348, Chicago, Illinois 60680. incidental Ss were given an orienting task that was designed to lead them to encode sentences semantically, their recall performance did not differ from the recall performance of $\mathrm{Ss}$ given intentional learning 
instructions. The recall performance of both these groups, however, was significantly superior to the performance of an incidental group that was given an orienting task that was designed to produce nonsemantic encoding of the sentences.

Rosenberg and Schiller were led by their findings, and the assumption that their intentional Ss were motivated to encode the sentences semantically, to suggest "... that the main contribution to learning efficiency of the intent to memorize the sentences was semantic coding during input [p. 346]." Unfortunately, Rosenberg and Schiller only used sentences that contained strong semantic constraints (e.g., The thief stole the money; The maid cleaned the house), and consequently, their failure to find a positive effect on recall performance of the activities other than semantic coding that intentional learners engage in (as well as the magnitude of the effect of semantic coding on incidental recall performance), could have been due to the nature of the sentences they used. Clearly, the relationships that are revealed by semantic encoding of such sentences are optimal for organization during storage and thus for subsequent recall performance as well (Rosenberg, 1969; Rosenberg \& Jarvella, 1970).

The present experiment was designed to evaluate the generality of Rosenberg and Schiller's results. In it, independent groups of Ss were presented with either sentences that were meaningful but weak in semantic constraint (e.g., The thief chose the basket; The maid bought the chair) or sentences in which the nouns violated semantic selectional restrictions on the verbs (e.g., The ball washed the chair; The shoe bit the wagon), under conditions that were identical to the conditions employed by Rosenberg and Schiller. Thus, Ss were exposed to either normal or anomalous sentences.

Semantic encoding of the anomalous sentences was expected to result in representations of the words they contain that would facilitate recall. However, it was also anticipated that without the integrating effect of normal semantic relations, the effect of semantic coding would be smaller for anomalous sentences than for normal sentences, with the additional activities associated with intentional learning being less important for normal sentences than for anomalous sentences.

Findings similar to Rosenberg and Schiller's for different semantic (imagery rating) and nonsemantic (pronunciability rating) orienting tasks have been reported by Anderson and Hidde (1972) for sentences that were meaningful but low in semantic constraint. Indeed, even though their nonsemantic task required (unlike letter estimation) whole sentence processing, there were over three times as many words recalled after imagery rating than were recalled after pronunciability rating. Unfortunately, these investigators did not include an intentional learning condition in their study.

\section{METHOD}

Three conditions of orientation to the materials (incidental-nonsemantic, incidental-semantic, and intentional-only) and two levels of semantic constraint (normal and anomalous sentences) were combined and presented to six independent groups.

\section{Subjects}

The Ss were 120 students from introductory psychology who participated in the study as part of a course requirement. They were assigned to six groups of $20 \mathrm{Ss}$ each withou t bias.

\section{Materials}

The materials consisted of a list of 12 normal and a list of 12 anomalous sentences of the form article - noun (singular) - verb (past tense) - article - noun (singular). Examples of the sentences have already been given. Both length (average number of letters) and Thorndike-Lorge (1944) word frequency were comparable for the two lists. The majority of the words in the two lists were high-frequency items. Associative sentence norms (Rosenberg \& Koen, 1968) were consulted to make certain that none of the verbs or objects in the two lists of sentences occurred with a frequency greater than one as responses to their subject nouns. In addition, the norms made it possible to minimize within-list semantic constraints. The anomalous sentences were constructed by linking transitive verbs that take animate subjects with inanimate subjects. Too, there were at least four instances in which an object noun violated semantic selectional restrictions on its verb.

The lists appeared in booklets, one sentence to a page. Each sentence in the incidental-nonsemantic condition was accompanied by a line on which the letter estimation was recorded, while in the incidental-semantic condition, there were scales numbered from 1 to 5 for the familiatity ratings. Four different orders of the lists were used.

\section{Procedure}

As in the earlier investigation by Rosenberg and Schiller (1971), the Ss in each condition were tested simultaneously, with the incidental groups being tested before the intentional groups. This procedure assured security in regard to incidental learning. A rotation procedure was used to distribute the booklets for the different sentence orders after the Ss had seated them selves in a quiet classroom. The incidental-nonsemantic task was to estimate the number of letters in each sentence, and the incidental-semantic task was to rate the sentences on the scale of familiarity. Intentional-only Ss, however, had only to try to memorize as many of the sentences as they could in any order. Written free-sentence recall followed a single list presentation. The recall instructions encouraged both partial recall and guessing. The sentence exposure interval was $7 \mathrm{sec}$, the intersentence interval $1 \mathrm{sec}$, and the recall period $5 \mathrm{~min}$. Forty seconds of instructions preceded written recall. Additional details of the procedure can be found in Rosenberg and Schiller (1971).

\section{RESULTS AND DISCUSSION}

A postexperimental inquiry did not reveal any incidental Ss who had attempted to memorize the sentences. Table 1 contains the means for the various measures of recall. The measures were sentence recall, content-word recall without regard for location on the recall sheet, and percent sentence recall per opportunity (the measure of the tendency to recall the sentences in 
Table 1

Means for All Groups for the Various Measures of Recall

\begin{tabular}{lccc} 
& \multicolumn{3}{c}{ Measure } \\
\cline { 2 - 4 } Group & $\begin{array}{c}\text { Sentence } \\
\text { Recall }\end{array}$ & $\begin{array}{l}\text { Word } \\
\text { Recall }\end{array}$ & $\begin{array}{c}\text { Percent Sen- } \\
\text { tence Recall }\end{array}$ \\
\hline $\begin{array}{l}\text { Incidental-Nonsemantic } \\
\quad \text { Normal }\end{array}$ & .10 & 3.85 & 2.78 \\
$\quad \begin{array}{c}\text { Anomalous } \\
\text { Incidental-Semantic }\end{array}$ & .35 & 3.75 & 14.65 \\
$\quad$ Normal & & & \\
$\quad$ Anomalous & 4.80 & 17.35 & 71.29 \\
$\begin{array}{l}\text { Intentional-Only } \\
\quad \text { Normal }\end{array}$ & 1.60 & 8.55 & 34.58 \\
$\quad$ Anomalous & 4.40 & 17.15 & 61.28 \\
\hline$\quad$ & 2.15 & 12.30 & 34.09 \\
\hline
\end{tabular}

an all-or-none fashion). The first time one or more words from a presented sentence occurred in recall it was counted as an opportunity to recall the entire sentence. However, if one or more other words from the sentence occurred later on in recall, it was not counted as an opportunity to recall the entire sentence. Thus, the measure was 100 (number of sentences recalled divided by number of opportunities).

The trends in the means of Table 1 suggest, at least in the case of sentences and content words, that the intentional-only condition was superior to the incidental-semantic condition for anomalous sentences, but not for normal sentences (indeed, for normal sentences the means for the incidental-semantic condition were somewhat higher than their intentional-only counterparts), and that semantic coding facilitated incidental recall for both normal and anomalous sentences but to a greater extent for normal sentences.

The expectations of interest were evaluated by a set of planned orthogonal and nonorthogonal comparisons ${ }^{1}$ using an alternative to the analysis of variance, the Bonferroni $t$ statistic (Kirk, 1968) with $p=.05$. This test takes as its error term the mean square within groups of the analysis of variance. However, because of the presence of a large number of zeros in the letter estimation condition for both normal and anomalous sentences for sentence recall and percent sentence recall per opportunity, it was not possible to carry out all the statistical tests of interest. The main comparisons of interest, however, could be tested statistically for all dependent variables, with results that revealed (a) no significant interactions between the incidental-semantic vs intentional-only conditions and the normal vs anomalous sentences, and (b) no significant differences between the incidental-semantic and intentional-only conditions for either normal or anomalous sentences. ${ }^{2}$ The degrees of freedom for the comparisons involving sentences and percent sentence recall per opportunity was 76, while for the comparisons involving content words, it was 114 . Thus, contrary to expectation, it does not appear that the activities other than semantic coding that intentional learners engage in facilitated recall performance for either normal or anomalous sentences.

The other comparisons of interest related to the question of the magnitude of the effect of semantic coding on incidental recall performance, but these comparisons for reasons already mentioned, could only be evaluated statistically for word recall. In this instance, the interaction between orienting task and semantic constraint for the incidental learners was significant well beyond the .05 level, as were the differences between the incidental-nonsemantic and incidental-semantic conditions for both the normal and anomalous sentences. In addition, while it was not possible to carry out statistical tests for these comparisons for sentence recall and percent sentence recall per opportunity, the means in Table 1 suggest strongly that the magnitude of the effect of semantic coding on incidental recall was substantially greater for normal sentences than for anomalous sentences for both these dependent variables. It seems reasonable to conclude then that recall performance for both the normal and anomalous sentences was facilitated by semantic coding, but to a greater extent for normal sentences than for anomalous sentences.

The present findings extend earlier observations (Anderson \& Hidde, 1972; Rosenberg \& Schiller, 1971). Regardless of variations in semantic constraint within sentences, the main contribution of intentionality to recall and organization appears to be semantic coding during input. In addition, it is clear that the effect of semantic coding on incidental recall performance is reduced when such coding does not make available to the language user at least normal intrasentence semantic relations.

\section{REFERENCES}

Anderson, R. C., \& Hidde, J. L. Imagery and sentence learning. Journal of Educational Psy chology, 1971, 62, 526-530,

Kirk, R. E. Experimental design. Belmont, California: Brooks/Cole, 1968.

Rosenberg, $S$. The recall of verbal material accompanying semantically well-integrated and semantically poorly-integrated sentences. Journal of Verbal Learning \& Verbal Behavior, 1969, 8, 732-736.

Rosenberg, S., \& Jarvella, R. J. Semantic integration and sentence perception. Journal of Verbal Learning \& Verbal Behavior, 1970,9, 548-553.

Rosenberg, S., \& Koen, M. J. Norms of sequential associative dependencies in active declarative sentences. In J. C. Catford (Ed.), Studies in language and language behavior, supplement to progress report VI. Ann Arbor: University of Michigan, Center for Research on Language and Language Behavior, U.S.O.E. Contract OEC-3-6-06178 4-0508. February 1. 1968

Rosenberg, S., \& Schiller, W. J. Semantic coding and incidental sentence recall. Journal of Experimental Psychology, 1971, 90, 345-346.

Thorndike, E. L., \& Lorge, I. The teacher's word book of 30,000 words. New York: Teachers College, 1944.

\section{NOTES}

1. The authors are indebted to L. P. Kroeker for his many helpful suggestions concerning multiple comparisons.

2. All comparisons involving percent sentence recall per opportunity were made after conversion to proportions and arcsin transform ation.

(Received for publication March 29, 1974.) 